\title{
Induction of a cell wall variant of the gonococcus by human amylase
}

\author{
A MELlERSH, S HAFIZ, M G MCENTEGART, AND I GEARY \\ From the Department of Medical Microbiology, University of Sheffield Medical School, Sheffield
}

SUMMARY Human amylase has been shown to be an effective and powerful inhibitor of the gonococcus in vitro. Its action appears to be on the bacterial cell wall. When tested in osmotically stabilised liquid media the organism was not inhibited; however the organisms which grew in such cultures appeared to be cell wall variants, which were less sensitive to penicillin than the parent strains. Studies on these variants suggest that they are "transitional-phase variants." Since cervical mucus has much in common with an alkaline osmotically stabilised liquid medium and also contains a high concentration of amylase, it seems possible that these variants may occur in vivo.

\section{Introduction}

Normal human saliva is a potent and specific inhibitor of the gonococcus in vitro, and this effect has been shown to be due to amylase. ${ }^{1}$ High concentrations of amylase are found in saliva, cervical mucus, ${ }^{2}$ and seminal fluid, ${ }^{3}$ and yet the gonococcus appears to survive in areas bathed by these fluids.

Because of its high molecular weight, about 50000 daltons, it seems probable that amylase acts at the level of the outer cell wall and does not penetrate the bacterium. Inhibitors of bacteria that act at the level of the cell wall are known to induce cell-walldefective, osmotically fragile variants. ${ }^{4}$

A major difference between growth of the gonococcus in vivo and in vitro is that in the former the body supplies a degree of osmotic stability; we felt that this protection-of an osmotically fragile, cell-wall-defective variant-might explain the survival of the gonococcus in the areas containing high concentrations of amylase.

\section{Materials and methods}

MEDIA

The liquid medium used was $\mathbf{A N M},^{5}$ and this was osmotically stabilised by the addition of $1 \%$ polyvinylpyrrolidone (BDH, Analar; molecular

Address for reprints: Professor M G McEntegart, Department of Medical Microbiology, University of Sheffield Medical School, Beech Hill Road, Sheffield S10 2RX

Received for publication 14 May 1979 weight, 700000 ); this is referred to as the liquid medium. Subcultures were made on to plates of Difco GC agar base with $2 \%$ defined supplement. When plates were to be osmotically stabilised $1 \%$ polyvinylpyrrolidone (BDH) was added. Subcultures from the liquid medium were made on both osmotically stabilised (OS) plates and non-stabilised (NOS) plates. Normally, ANM has a pH of $7 \cdot 2$, but some of the liquid media was adjusted with sodium hydroxide, $(1 \mathrm{~mol} / \mathrm{l})$ to a $\mathrm{pH}$ of 8.0 (the $\mathrm{pH}$ of the cervical mucus of a woman on the contraceptive pill).

\section{N GONORRHOEAE STRAINS}

International strain WHO VII, $\beta$-lactamase producers $\mathrm{HKI}$ and $\mathrm{RI}$, as well as recent isolates from the Sheffield Special Clinic, were used for this study.

\section{AMYLASE EXTRACTION}

Amylase was extracted from pooled human saliva by the method of Meyer et al. ${ }^{6}$ Purified amylase was added to the liquid media to give a final amylase activity of approximately 2000 Somogyi units per $\mathrm{ml}$.

\section{STAINING}

Cultures were centrifuged at $2000 \mathrm{rev} / \mathrm{min}$ for 10 minutes and the deposit washed with phosphatebuffered saline, placed on slides, and stained using Dienes or Gram stain.

\section{MILLIPORE FILTRATION}

Eighteen-hour cultures in stabilised liquid medium were passed through $0.45 \mu$ Millipore filters and the filtrate cultured in stabilised liquid medium as well as on OS and NOS plates. 
IMMUNOFLUORESCENCE

A loopful of suspension prepared from the centrifuged deposit was allowed to dry in air on a standard microscope slide, fixed in acetone, and covered with a 1/16 dilution of antigonococcal immunofluorescent conjugate (Bacto-FA $N$ gonorrhoeae Difco). Slides were left in a moist box for 15 minutes, washed in distilled water, dried, and mounted in glycerol buffer for examination.

\section{ELECTRON MICROSCOPY}

Centrifuged deposits were suspended in $3 \%$ buffered gluteraldehyde for one hour and then post-fixed with $1 \%$ osmium tetroxide for 30 minutes, prestained with uranyl acetate for 30 minutes, and dehydrated through increasing concentrations of ethyl alcohol to epoxy propane and finally embedded in epoxy resin. Ultra-thin sections were cut using a Reichert OMU 3 ultramicrotome. The thickness of sections ranged from 60 to $80 \mathrm{~nm}$. The sections were mounted on copper grids and stained with Reynolds lead citrate.

\section{ENDOTOXIN ASSAY (CHICK EMBRYO TESTS)}

Eighteen-hour cultures of WHO VII strain gonococci grown in the liquid medium with amylase were centrifuged and the deposit resuspended in saline and standardised with an EEL nephelometer to contain $10^{6}$ organisms per $\mathrm{ml}$. For the test, 10-day-old embryonated eggs were used. These were kept in a humidified incubator at $37^{\circ} \mathrm{C}$. For inoculation, a rectangular window (approximately $3 \times 5 \mathrm{~mm}$ ) was cut over a prominent allantoic vein (while candling) and the shell flap was lifted off with a needle. After the windows had been cut the eggs were undisturbed for one hour to minimise bleeding on inoculation; $0.1 \mathrm{ml}$ of the suspensions was inoculated into each egg with a 27-gauge needle. Control eggs received a suspension of vegetative-phase bacteria at the same concentration or, as a negative control, phosphatebuffered saline. After inoculation, the eggs were returned to the incubator for two days and were candled at 24 and 48 hours. When death of the embryo was suspected, it was confirmed by immediate examination of the contents of the egg. Specific endotoxin deaths showed very characteristic pathological changes and usually occurred in the first 24 hours after inoculation.

\section{PENICILLIN SENSITIVITY}

Benzyl penicillin was diluted in the liquid medium to give a series of dilutions from 1.0 to 0.0025 units per $\mathrm{ml}$ as shown in the table. Amylase and $0.1 \mathrm{ml}$ of an 18-hour culture of WHO VII strain gonococci (in the liquid medium with amylase) were added to each dilution. WHO VII strain gonococci grown without amylase and the Oxford Staphylococcus were added
TABLE Sensitivity of two strains of $N$ gonorrhoeae and the Oxford Staphylococcus to benzyl penicillin

\begin{tabular}{lllllll}
\hline & $\begin{array}{l}\text { Concentrations of penicillin } \\
\text { (units per ml) }\end{array}$ & & & \\
\cline { 2 - 6 } Organisms & 1.0 & 0.1 & 0.05 & 0.01 & 0.005 & 0.0025 \\
\hline $\begin{array}{l}\text { Staphylococcus Oxford } \\
\text { (control) }\end{array}$ & - & + & + & + & + & + \\
$\begin{array}{l}\text { WHO VII vegetative phase } \\
\text { (non-amylase treated) }\end{array}$ & - & - & - & - & + & + \\
$\begin{array}{l}\text { WHO VII variant phase } \\
\text { (amylase-treated) }\end{array}$ & - & + & + & + & + & + \\
\hline+ Growth - no growth & & & & & &
\end{tabular}

to two similar series of penicillin dilutions as controls. Penicillinase production was detected by the addition of a chromogenic cephalosporin (Nitrocefin, Glaxo).

\section{Results}

CULTURE GROWTH AND STAINING

In the osmotically stabilised liquid media, all strains showed visible growth in $\mathbf{1 8}$ hours. Subcultures made on OS and NOS plates at 18 hours all grew. Colonies were more numerous on OS plates, especially on subcultures made more than $\mathbf{4 8}$ hours after inoculation of the liquid media. On some occasions no growth was obtained on NOS plates after 48 hours. When examined in wet preparation the growth in the liquid medium was typically seen as clumps of organisms up to $2 \mathrm{~mm}$ in diameter. Growth in the medium at $\mathrm{pH}$ 8.0 was similar to that at $7 \cdot 2$. The colonial forms on primary subculture from the liquid medium on to solid medium were of three types. Most were typical gonococcal colonies. A varying number, up to $50 \%$, were atypical with a raised circular centre and a flat periphery with a well defined border. Subsequent subcultures from these colonies yielded typical gonococcal colonies of Gram-negative diplococci which fermented glucose but not maltose or sucrose. About $1 \%$ of colonies were of the $L$ form. Dienesstained films of 18-hour cultures showed aggregates of weakly staining granular material with a few darker staining diplococci (fig 1). These aggregates were Gram-negative and, when tested with a known antigonococcal serum, showed bright on specific fluorescence (fig 2). Millipore filtration was unsuccessful in that only a few viable units passed through the filter.

\section{ELECTRON MICROSCOPY}

On electron microscopy the control organisms incubated without amylase (fig 3) had a uniform shape, typical cell wall structure, and an osmophilic cytoplasm indicating a large number of ribosomes. 


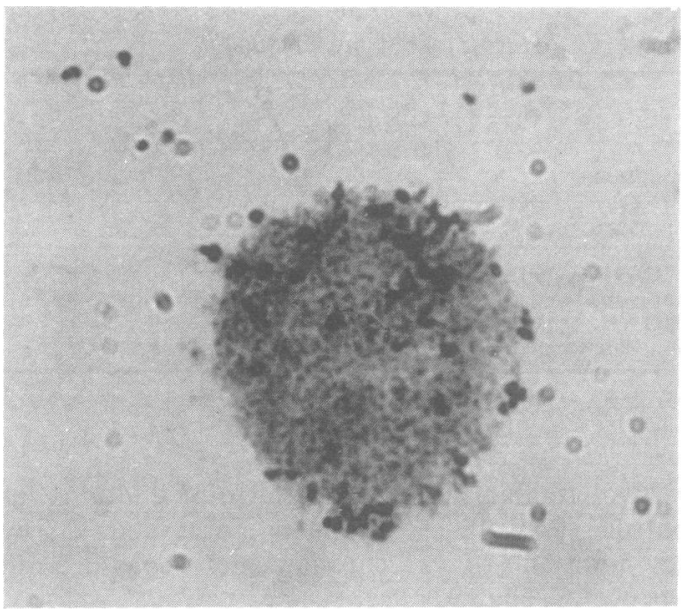

FIG 1 Impression preparation of an L-form colony grown from a subculture of gonococci exposed to amylase in liquid medium for 18 hours. Dienes stain $\times 1230$.

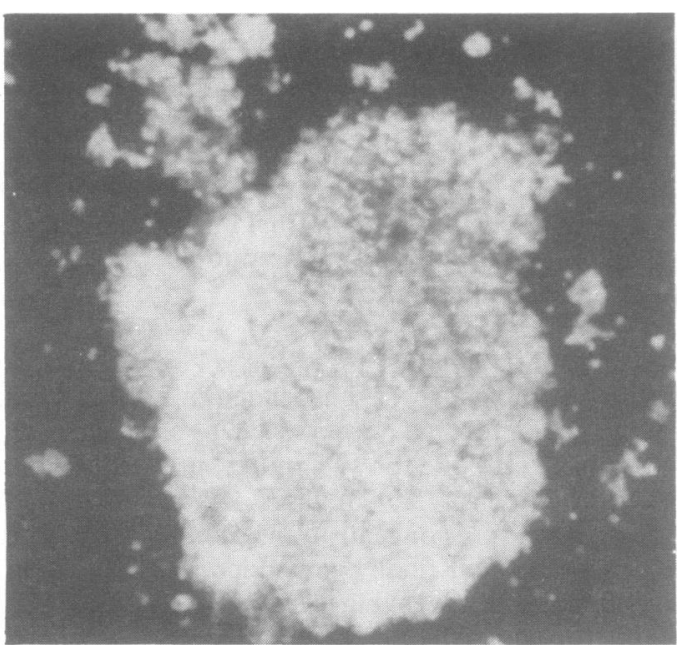

FIG 2 Impression preparation of L-form colony showing bright fluorescence when stained with a specific antigonococcal conjugate. $\times 1230$.

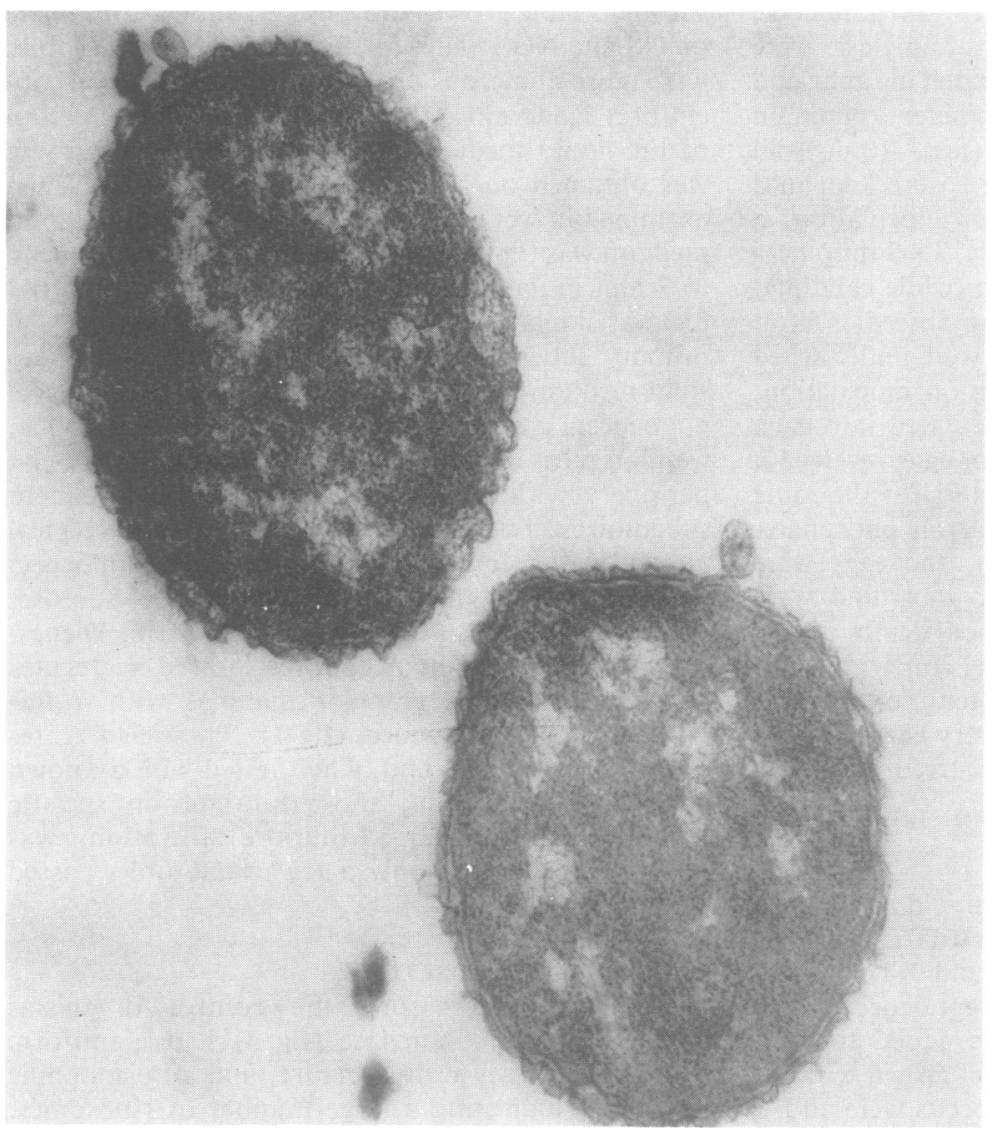

FIG 3 Electron micrograph ( $\times 54$ 500) showing normal appearance of control gonococcus. 


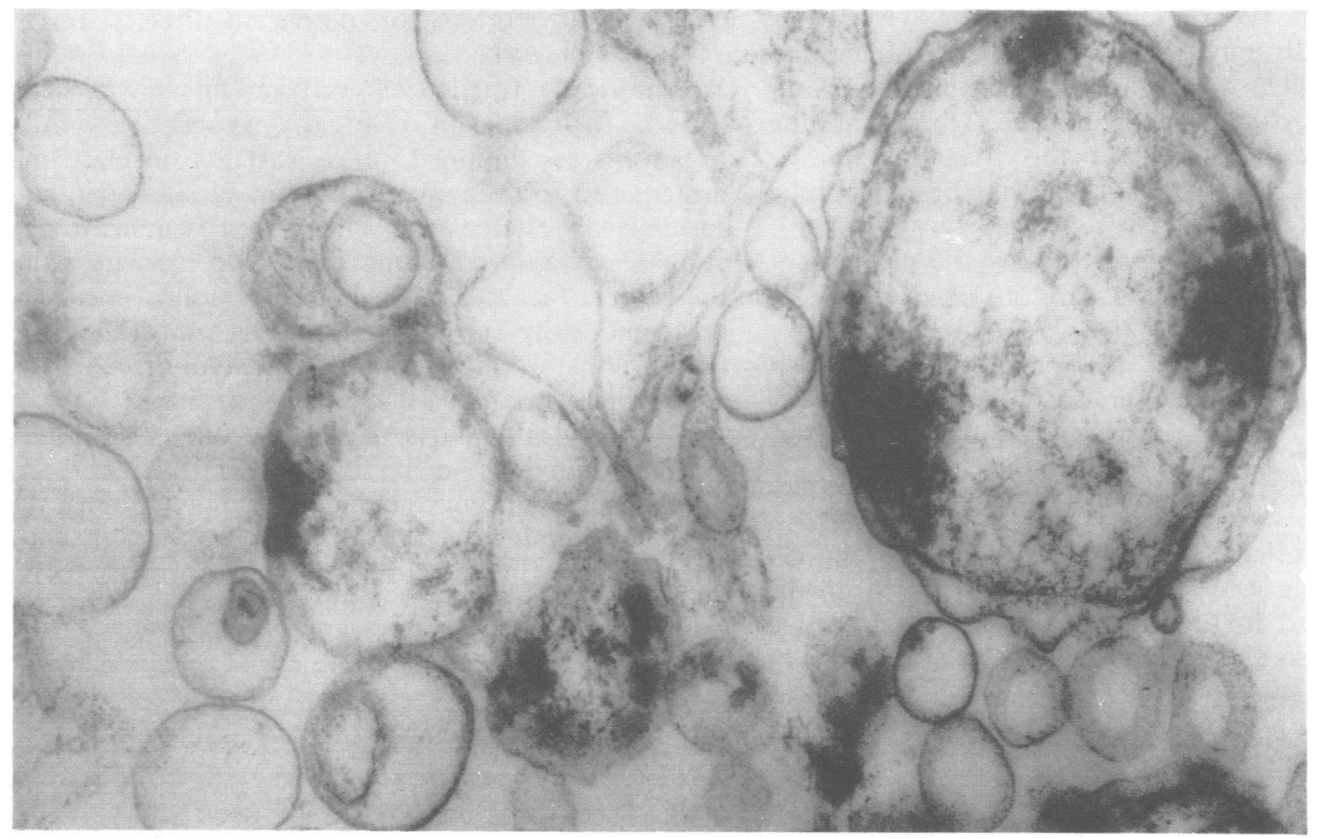

(a)

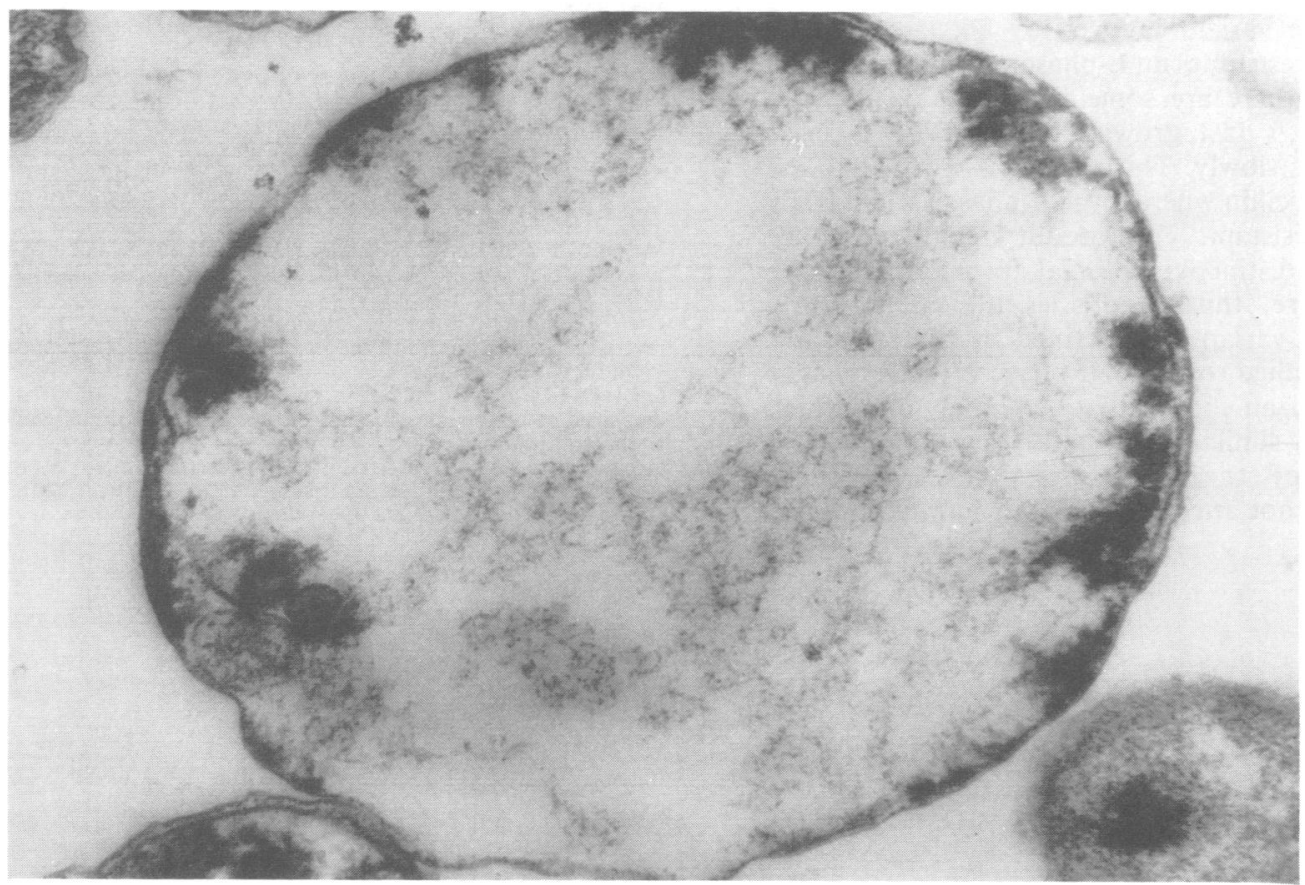

(b)

FIG 4 (a) and (b) Electron micrographs $(\times 54500)$ of amylase-treated gonococci showing gross variation in cell size and damage to the cell wall. 
They showed typical endotoxin blebs. Organisms incubated with amylase were irregular in shape and size (fig 4); they were limited by a simple cell wall, often just a cytoplasmic membrane. This membrane was often duplicated and the inner membrane discontinuous. In larger organisms the osmophilic material was less and scattered at the periphery. Numerous smaller units resembling the elementary bodies of L-phase variants were observed, but these were presumably not viable, as viable units were rarely obtained after Millipore filtration. No endotoxin blebs were observed.

\section{ENDOTOXIN ASSAY}

The organisms grown in the liquid medium containing amylase were toxic to chick embryos $(70 \%$ endotoxic deaths) but not as toxic as the vegetativephase bacteria ( $90 \%$ endotoxic deaths). No deaths were observed in the controls. (Each of the three groups consisted of $\mathbf{3 0}$ chick embryos.) The growth in the liquid media with amylase was still sensitive to penicillin but not as sensitive as the vegetative-phase bacteria (table). $\beta$-lactamase-producing bacteria continued to produce $\beta$-lactamase throughout the experiments.

\section{Discussion}

Although the variant induced by amylase in these experiments resembles an $\mathrm{L}$-phase variant on electron microscopy, there are some important differences. This variant is fast growing whereas the L-phase variant grows slowly. This variant is sensitive to the action of penicillin whereas the L-phase variant is, by definition, resistant. This variant cannot reproduce serially in a distinctive colonial form on agar. We feel, therefore, that it satisfies the criteria of a "transitional variant" as defined by McGee et al. Ota et $\mathbf{l}^{8}$ studied reverting L-phase variants on agar and observed an intermediate colonial form which was strikingly similar to those forms we observed on subculture of these variants. However, these workers $^{8}$ did not attempt to grow it in liquid media, study its properties, or derive it directly from vegetative bacteria.

Osmotically fragile cell wall variants have been shown to occur in clinical gonorrhoea ${ }^{9}$ and organisms resembling L-phase variants on electron microscopy have been observed in clinical specimens. ${ }^{10}$ These variants have been assumed to be L-phase variants, although this is inconsistent with the clinical fact that penicillin cures gonorrhoea. If the osmotically fragile fraction was transitional in nature, this would be more consistent, since this transitional variant is sensitive to penicillin.

The cervical mucus is osmotically stabilised, contains amylase in high concentration, and is alkaline. Attempting to simulate these conditions in vitro, we obtained a transitional-phase variant, and we consider therefore that it is likely that these variants occur in vivo and may have a part in explaining the relatively asymptomatic nature of infections of the uterine cervix.

\section{References}

1. Mellersh A, Clark A, Hafiz S. The inhibition of $N$ gonorrhoeae by normal human saliva. Br J Vener Dis 1979;55:20-3.

2. Gregoire AT, Rankin J, Rakoff AE, Adams A. $\alpha$-amylase content in cervical mucus of females receiving sequential, nonsequential, and no contraceptive therapy. Fertil Steril 1967; 18: 836-9.

3. Goldblatt MW. Constituents of human seminal plasma. Biochem 1935; 29: 1346-57.

4. Butler HM, Blakey JL. A review of bacteria in L-phase and their possible clinical significance. Med J Aust 1975;2:463-7.

5. Hafiz S, McEntegart MG. Prolonged survival of $N$ gonorrhoeae in a new liquid medium. Br J Vener Dis 1976;52:381-3.

6. Meyer KH, Fischer H, Bernfeld P, Staub A. Purification et crystallisation de l' $\alpha$-amylase de salive. Experientia 1947;3:455.

7. McGee ZA, Whittler RG, Gooder H, Charache P. Wall defective microbial variants: terminolosy and experimental design. $J$ Infect Dis 1971;123:433-8.

8. Ota F, Fukui K, Ashton FE, Diena BB. The fine structure of reverting L-forms of Neisseria gonorrhoeae. Jpn J Microbiol 1976; 20:59-62.

9. Gnarpe $\mathbf{H}$, Wallin J. Studies in venereal disease. II Improved diagnosis of gonorrhoea by parallel use of conventional and L-phase media for culture. Br J Vener Dis 1973;49:505-7.

10. Ovcinnikov, NM, Delektorskij VV. Electron microscope studies of gonococci in the urethral secretions of patients with gonorrhoea. Br J Vener Dis 1971;47:419-39. 